\title{
STUDY OF COMPARATIVE EFFICACY AND ADVERSE EFFECTS OF CAFFEINE AND AMINOPHYLLINE IN THE MANAGEMENT OF APNEA OF PREMATURITY: A RANDOMIZED CONTROL TRIAL
}

Maulik Korvadiya ${ }^{1}$, Rupesh Masand ${ }^{2}$, Alok Purohit ${ }^{3}$

\section{HOW TO CITE THIS ARTICLE:}

Maulik Korvadiya, Rupesh Masand, Alok Purohit. "Study of Comparative Efficacy and Adverse Effects of Caffeine and Aminophylline in the Management of Apnea of Prematurity: A Randomized Control Trial". Journal of Evolution of Medical and Dental Sciences 2014; Vol. 3, Issue 23, June 09; Page: 6361-6368,

DOI: $10.14260 /$ jemds/2014/2748

ABSTRACT: Background: Apnea of prematurity (AOP) is one of the most common respiratory disorder in the NICU. Methylxanthine derivatives have been administered to decrease the frequency of apneic episodes and prevent the need for assisted ventilation. AIMS: To compare the efficacy and adverse effects of caffeine and aminophylline in the management of AOP. Settings \& design: It is a non-inferiority, randomized control trial in the NICU of tertiary care hospital. MATERIAL \& METHODS: All intramural preterm neonates diagnosed as having AOP and satisfying the predefined inclusion criteria were randomized to receive either intravenous caffeine $(n=20)$ or intravenous aminophylline $(\mathrm{n}=20)$ as per standard dosage and schedule. Neonates whose apnea episodes were not controlled by the assigned drugs were subsequently subjected to CPAP/mechanical ventilation. Apnea frequency was calculated to assess and compare efficacy of the either drug. Requirement and response to $\mathrm{CPAP} /$ mechanical ventilation was observed and adverse reactions to the either drug noted in each case. Statistical analysis: It was carried out by chi-square test \& independent t-test. P value $<0.05$ was considered significant. RESULTS: A $>50 \%$ reduction in apnea frequency was observed with the use of caffeine or aminophylline at the end of Day 5 of management. There was no significant difference $(\mathrm{P}>0.05)$ in the apnea frequency between the two groups on days 0,1 and 5 . Requirement and response of $\mathrm{CPAP} /$ mechanical ventilation was similar $(\mathrm{P}>0.05)$ with the use of either drug. Adverse effects like feeding intolerance and vomiting were more frequently associated with aminophylline as compared to caffeine. CONCLUSION: Intravenous caffeine was as efficacious as intravenous aminophylline in management of AOP and associated with relatively less adverse effects. KEYWORDS: aminophylline, apnea of prematurity, caffeine.

INTRODUCTION: Apnea, defined as cessation of breathing for 20 seconds or longer or shorter duration in presence of cyanosis or bradycardia, is one of the most common respiratory disorders in the NICU. Apnea of prematurity (AOP) is a diagnosis of exclusion and should be considered only after secondary causes of apnea have been excluded in preterm neonates.[1] Since 1970s, methylxanthine derivatives have been administered both parenterally and orally to decrease the frequency of apneic episodes and prevent the need for assisted ventilation.

As aminophylline is known to have a narrow therapeutic window \& significant adverse effects, there arises a need to consider alternative drug(s) for better control of apnea with adequate safety profile. Caffeine attempts to fulfill this unmet need and is backed by sufficient data and extensive use in the Western world.

There have been few studies comparing the efficacy of theophylline and caffeine in managing AOP in the West, $[2-8]$ but practically none in the Indian pediatric population. We hypothesized that 


\section{ORIGINAL ARTICLE}

intravenous caffeine is as efficacious as intravenous aminophylline and associated with relatively less adverse effects in the management of preterm neonates with AOP.

MATERIAL AND METHODS: This non-inferiority, randomized control study was conducted in the NICU of a tertiary care hospital in India from January 2012 to June 2013. Ethical clearance for the study was obtained from the Institutional Ethical Committee. Informed consent from the parents/ guardians of study subjects was taken in the local vernacular. The study included 40 preterm neonates of 28-36 wks of gestational age with weight between 1 to $2 \mathrm{kgs}$ who had 2 or $>2$ episodes of apnea in last 24 hrs, not explained by any other cause during day 3 till day 7 of life.

Preterm neonates with weight $<1 \mathrm{~kg}$, presence of major congenital anomalies, babies who required resuscitation at birth or babies with other identifiable causes of apnea (respiratory distress and/or hypoxemia, patent ductus arteriosus, anemia, hypoglycemia, hypocalcemia, hypothermia, hyperbilirubinemia, sepsis, intra-ventricular hemorrhage) were excluded after performing relevant investigations according to standard NICU protocol.

A sample size of 20 in each group with an $\alpha$ error of $5 \%$ and $90 \%$ power in a two sided test was required. The study subjects were randomized to receive either Drug A (Aminophylline, $\mathrm{n}=20$ ) or Drug B (Caffeine, $n=20$ ). Randomization was done using small square slips with computer generated numbers. These pre- numbered slips were folded and shuffled in a box and opened for each neonate to decide the intervention.

Neonates with odd numbered slips were administered Drug A (Aminophylline). Neonates with even numbered slips were administered Drug B (Caffeine). This was done by a person not involved in the study. The nursing staff \& posted doctors were aware of this allocation. The authors were blinded during process of allocation and administration. After randomization, study subjects in both the caffeine \& aminophylline-treated groups were further categorized according to their gestational age on admission- Group A (28-30 wk), Group B (31-33 wk), and Group C (34-36 wk) (Fig. 1). The clinical profile of the study subjects was recorded in a pre-structured proforma.

Intravenous aminophylline was administered as loading dose of $5 \mathrm{mg} / \mathrm{kg}$ followed by $2 \mathrm{mg} / \mathrm{kg}$ TDS as maintenance dose, initiated $12 \mathrm{hrs}$ after the loading dose. Aminophylline was diluted in $10 \mathrm{ml}$ of normal saline and administered over 15-20 minutes on each occasion. Intravenous caffeine (caffeine citrate, $20 \mathrm{mg} / \mathrm{ml}$ preparation) was administered as a loading dose of $20 \mathrm{mg} / \mathrm{kg}$ and later maintenance as $5 \mathrm{mg} / \mathrm{kg}$ OD, commenced $24 \mathrm{hrs}$ after the loading dose. Caffeine was diluted in $30 \mathrm{ml}$ of normal saline and given over 15-20 mins.[9,10]

Both the drugs were given for 7 days after the last episode of apnea or till 34 wks of maturity, whichever occurred earlier. We could not measure blood levels of either drug in our setup. Patients were monitored by using apnea monitor and pulse oximeter for recurrence of apnea and adverse effects.

Protocol for using secondary intervention: Continuous positive airway pressure (CPAP) was initiated in the study subjects receiving aminophylline or caffeine, if a). $>1$ episode of apnea requiring either bag \& mask ventilation (BMV) or oxygen supplementation occurred within 6hrs or b). $>1$ episode of apnea (spontaneous) occurred every hour for 6hrs. Patients who continued to exhibit episodes of apnea inspite of CPAP support were subjected to mechanical ventilation.[11]

Efficacy of the drug was defined as the ability to achieve a $>50 \%$ reduction in number of episodes of apnea (as compared to previous) at the end of day 5 of initiation of treatment. 


\section{ORIGINAL ARTICLE}

Primary outcome was to compare the efficacy of aminophylline and caffeine in management of AOP which was done by calculating the 'apnea frequency' on the day of initiating the either drug ('day 0 ') followed by $24 \mathrm{~h}$ after the loading dose ("day 1 ") and again four days later ("day 5 ") using cardiorespiratory monitoring data.. Apnea frequency was defined as the average number of apneic attacks per 100 minutes. ${ }^{[2]}$

Secondary outcome was the requirement of other modalities of intervention for control of apnea (CPAP/ Mechanical ventilation) and adverse reactions to both drugs in study subjects. The outcomes were compared between aminophylline or caffeine treated groups with respect to their gestation age on admission. Adverse reactions to both the drugs like tachycardia, jitteriness, seizure, hyperglycemia, vomiting, feeding intolerance, signs and symptoms of NEC were noted. For the purpose of this study, vomiting was defined as any episode of expulsion of gastric contents with effort which could be projectile in nature and the perception of the staff nurse that the infant had episodes of gag.

Vomiting was some time after feeding and it contained altered milk. Feed intolerance was defined as (i) more than 2 episodes of vomiting in any $4 \mathrm{hrs}$ period, or $>3$ in $24 \mathrm{hrs}$ and/or, (ii) abdominal distension defined as increase in abdominal girth by $2 \mathrm{cms}$ from base line (checked only if repeated vomiting) and/or (iii) or if gastric residual volume is $>2 \mathrm{ml}$ undigested milk. Statistical analysis was carried out using SPSS statistical 17 software for Windows. Chi-square test was performed for data analysis of qualitative variables. The mean value of the two groups was compared using independent t-test. $P$ value $<0.05$ was considered significant.

RESULTS: Out of 40 babies with AOP, 20 were randomized to receive Aminophylline (Drug A) and the remaining received caffeine (Drug B). Baseline characteristics were comparable in among the aminophylline and caffeine treated subjects (Table 1). As compared to day 0 , the 24-hour recordings on days 1 and 5 showed significant decrease in the apnea frequency in both aminophylline-treated and caffeine-treated neonates ( $\mathrm{P}>0.05)$. There was no significant difference in the apnea frequency between the two groups, on days 0,1 , and 5 (Table 2). 26(65\%) preterm neonates had achieved > $50 \%$ reduction in apnea rates by end of 5 days with either caffeine or aminophylline while the rest $14(35 \%)$ could not achieve $>50 \%$ reduction in apneic episodes by the end of day 5 .

According to gestational age on admission, patients were divided into Group A (28-30wks), Group B (31-33wks), and Group C (34-36wks). In Group A, caffeine was observed to be effective in $83.34 \%$ study subjects as compared to aminophylline which was effective in $57.15 \%$ study subjects $\left(\chi^{2}=0.17, \mathrm{P}=0.67\right)$.In Group $\mathrm{B}$, caffeine was observed to be effective in $62.5 \%$ study subjects as compared to aminophylline which was effective in $62.5 \%$ study subjects $\left(\chi^{2}=0.26, \mathrm{P}=0.60\right)$.In Group $\mathrm{C}$, caffeine was observed to be effective in $66.6 \%$ study subjects as compared to aminophylline which was effective in $60 \%$ study subjects $\left(\chi^{2}=0.16, \mathrm{P}=0.68\right)$ (Table 3 )

Episodes of apnea could not be controlled in 14 patients with the use of either aminophylline or caffeine. CPAP was initiated in all 14 patients out of whom 4 required enhanced support by mechanical ventilation. In Group A, 3(28.5\%) of the aminophylline -treated neonates responded to $\mathrm{CPAP} /$ mechanical ventilation and $1(16.6 \%)$ in caffeine treated group $\left(\chi^{2}=0.17, \mathrm{P}=0.67\right)$. In Group $\mathrm{B}$, $3(37.5 \%)$ of the aminophylline treated preterm neonates responded to CPAP/mechanical ventilation and $3(37.5 \%)$ in caffeine treated group $\left(\chi^{2}=0.26, \mathrm{P}=0.60\right)$. 


\section{ORIGINAL ARTICLE}

In Group C, 2(40\%) of the aminophylline-treated preterm neonates responded to $\mathrm{CPAP} /$ mechanical ventilation and $2(33.34 \%)$ in caffeine- treated group $\left(\chi^{2}=0.16, \mathrm{P}=0.68\right)$. Thus, no significant difference was observed in control of apnea by secondary intervention in aminophylline and caffeine treated subjects.

The common adverse effects observed during the study were feeding intolerance and vomiting in both the caffeine \& aminophylline-treated subjects. Feeding intolerance was observed in 2 cases (10\%) of caffeine group as compared to 4 cases $(20 \%)$ in the aminophylline group. Vomiting was seen in 4 cases $(20 \%)$ of caffeine group as compared to 6 cases $(30 \%)$ in the aminophylline group. Adverse effects like feeding intolerance $\left(\chi^{2}=0.41, \mathrm{P}=0.52\right)$ and vomiting $\left(\chi^{2}=0.35, \mathrm{P}=0.54\right)$ were more frequently associated with the use of aminophylline than caffeine, though statistically, the comparison between the two drugs, for these adverse effects, was insignificant $(\mathrm{P}>0.05)$.

Mortality was observed in 3 cases, beyond day 10 of life, in 1 caffeine-treated and 2 aminophylline-treated subjects which was associated with prematurity and late onset sepsis.

DISCUSSION: Intravenous caffeine was observed to be as efficacious as intravenous aminophylline during management of AOP in preterm neonates. In our study, as compare to day 0 , there was significant decreases of apnea frequency in both aminophylline and caffeine treated preterms on days 1 and 5. There was no significant difference in the frequency of apnea between the two groups, on days 0, 1 and 5. These observations are similar to those of Brouard et al.[2] 26 (65\%) preterm neonates had achieved $>50 \%$ reduction in apnea rates by end of 5 days with either aminophylline or caffeine while the rest 14 (35\%) could not achieve the same.

Here both aminophylline and caffeine were observed to be equally efficacious in reducing apneic episodes by $>50 \%$ by day 5 of treatment of AOP in preterm neonates. In the meta-analysis by Henderson Smart et al, ${ }^{[9]} 5$ trials ${ }^{[2,3,5,7,8]}$ involving a total of 108 infants were included. No difference in treatment failure rate was found between caffeine and theophylline after one to three days treatment ${ }^{[2,3]}$ or five to seven days treatment.[3]

Adverse effects were observed in 6(30\%) preterm neonates with caffeine and $10(50 \%)$ preterm neonates with aminophylline in this study. Bairam et al [3] observed adverse effects in $40 \%$ preterm neonates with aminophylline and none was observed with caffeine. Other studies have observed increased association of adverse effects with aminophylline compared with caffeine.[2,5] Adverse effects like vomiting/feeding intolerance were more frequently (numerically) associated with the use of aminophylline than caffeine, thought statistically, the comparison between the two drugs was insignificant ( $\mathrm{p}>0.05)$.

Erenberg et al[13] revealed an increased rate of NEC in caffeine treated preterm neonates with AOP. Conversely, the larger Schmidt study[14] identified no difference in rates of NEC between the caffeine and placebo groups. We did not observe tachycardia, jitteriness, seizure, hyperglycemia, signs and symptoms of NEC with the use of either drug during this study. In comparison to other studies, ${ }^{[2,3]}$ our study had a larger sample size. Further study subjects were categorized according to their gestational age and comparison of drug efficacy was performed subsequently.

However we could not monitor drug levels and correlate them with adverse effects due to lack of facilities in our set-up. Though, the safety profile of caffeine is well established in extremely low birth weight babies,[1] we could not include them, due to presence of co-morbidities that may have confounded this trial. Inability to blind the nursing staff and resident doctors in NICU may be a 


\section{ORIGINAL ARTICLE}

source of bias and limitation. Assessment of long term neurobehavioral impairment and incidence of broncho pulmonary dysplasia [14,15] associated with caffeine therapy could not be performed due to lack of adequate follow up.

CONCLUSION: Intravenous caffeine is as efficacious as intravenous aminophylline and associated with relatively less adverse effects in the management of preterm neonates with AOP. However, aminophylline is quite cheap as compared to caffeine \& may be preferred in our resource-limited settings.

\section{REFERENCES:}

1. Cloherty J P, Eichenwald E C, Hansen A R, Stark A R, Eds. Manual Of Neonatal Care. 7th edn. Philadelphia; Lippincott Williams \& Wilkins.2011; 397-402.

2. Brouard C, Moriette G, Murat I, et al. Comparative efficacy of theophylline and caffeine in the treatment of idiopathic apnea in premature infants. Am J Dis Child 1985; 139: 698-700.

3. Bairam A, Boutroy MJ, Badonnel Y, Vert P. Theophylline versus caffeine: comparative effects in treatment of idiopathic apnea in the preterm infant. J Pediatr 1987; 110: 636-639.

4. Davis JM, Spitzer AR, Stefano JL, et al. Use of caffeine in infants unresponsive to theophylline in apnea of prematurity. Pediatr Pulmonol. 1987; 3: 90-93.

5. Scanlon JE, Chin KC, Morgan ME, Durbin GM, Hale KA, Brown SS. Caffeine or theophylline for neonatal apnea? Arch Dis Child 1992; 67: 425-428.

6. Larsen PB, Brendstrup, Skov L, Fachs L. Aminophylline versus caffeine citrate for apnea and bradycardia prophylaxis in premature neonates. Acta Paediatr. 1995; 84: 360-364.

7. Fuglsang G, Nielsen K, Kjaer Nielsen L, Sennels F, Jakobsen P, Thelle T. The effect of caffeine compared with theophylline in the treatment of idiopathic apnea in premature infants. Acta Paediatrica Scandinavica 1989; 78:786-788

8. Kumar SP, Mehta PN, Bradley BS, Ezhuthachan SG. Documented monitoring (DM) shows theophylline $(\mathrm{T})$ to be more effective than caffeine $(\mathrm{C})$ in prematurity apnea (PA). Pediatric Research 1992; 31: 208A.

9. Henderson-Smart DJ, Steer PA. Caffeine versus theophylline for apnea in preterm infants. Cochrane Database of Systematic Reviews 2010, Issue 1. Art. No. CD000273. [doi: 10.1002/14651858.CD000273.pub2].

10. Comer AM, Perry CM, Figgitt DP. Caffeine citrate: a review of its use in apnea of prematurity. Pediatr Drugs 2001; 3: 61-79.

11. Aggarwal R, Shinghal A, Deorari AK, Paul VK. Apnea in the New born. http://www.newbornwhocc.org/pdf/apnea.pdf. Accessed 20 Aug 2012

12. Hoecker C, Nelle M, Poeschl J et al (2002) Caffeine impairs cerebral and intestinal blood flow velocity in preterm infants. Pediatrics 109 (5):784-787.

13. Erenberg A, Leff RD, Haack DG, Mosdell KW, Hicks GM, Wynne BA. Caffeine citrate for the treatment of apnea of prematurity: a double-blind, placebo-controlled study. Pharmacotherapy 2000; 20: 644-52.

14. Schmidt B, Roberts RS, Davis P, Doyle LW, Barrington KJ, et al. Long term effects of caffeine therapy for apnea of prematurity. N Engl J Med. 2007; 357: 1893-1902. 


\section{ORIGINAL ARTICLE}

15. Schmidt B, Anderson PJ, Doyle LW, Dewey D, Grunau RE, et al. Survival without disability to age 5 years after neonatal caffeine therapy for apnea of prematurity. JAMA. 2012; 307: 275-282.

7 Excluded:

3 had sepsis

2 had hypoglycemia

2 had hyaline membrane disease

47 Assessed for eligibility

40 Randomized

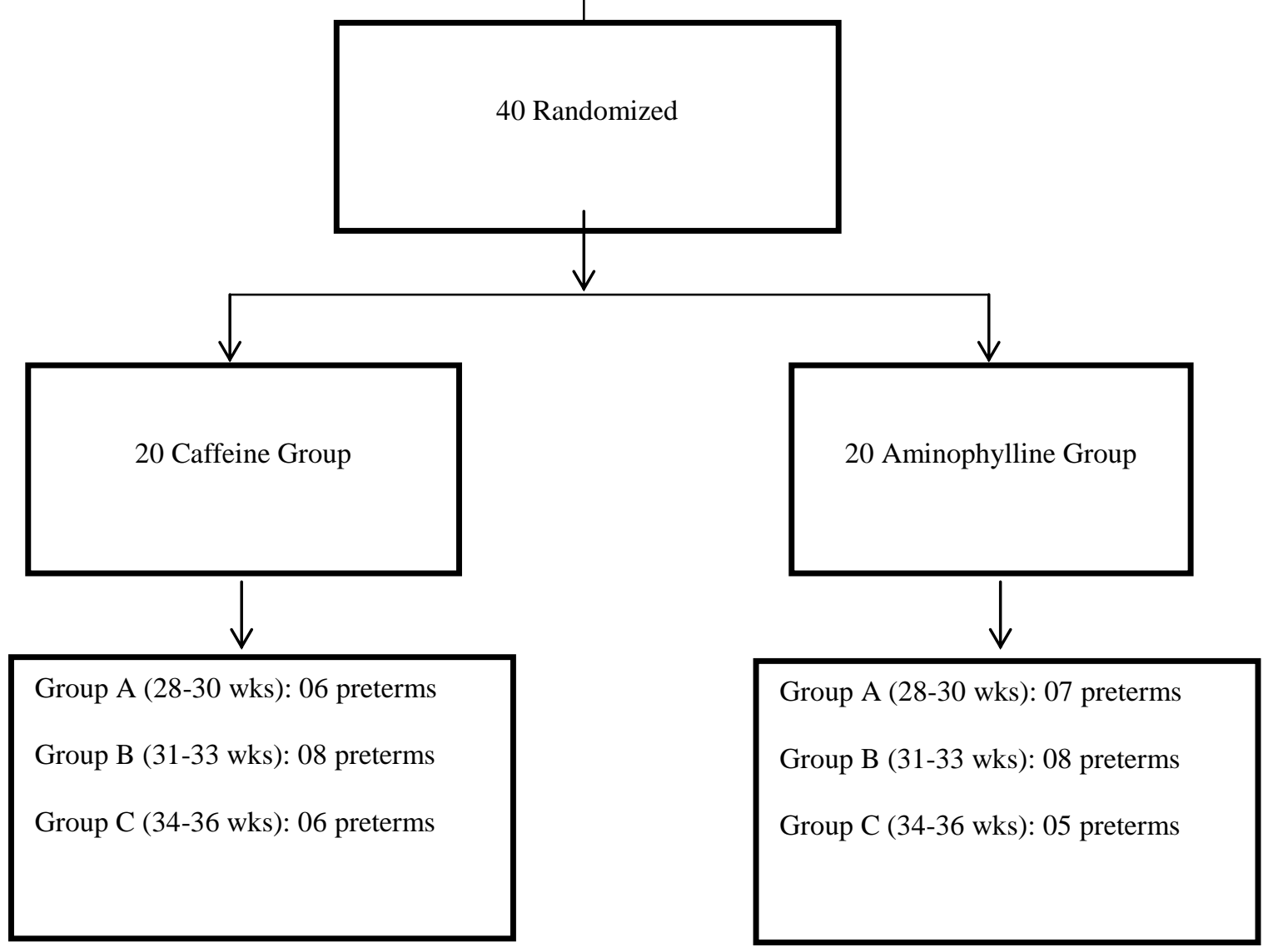

\section{Fig.1 Participant flow diagram}




\section{ORIGINAL ARTICLE}

\begin{tabular}{|l|c|c|}
\hline \multicolumn{1}{|c|}{ Characteristics } & $\begin{array}{c}\text { Aminophylline group } \\
(\mathbf{n = 2 0 )}\end{array}$ & $\begin{array}{c}\text { Caffeine group } \\
\text { (n=20) }\end{array}$ \\
\hline Birth weight (g) & $1.43 \pm 0.27$ & $1.44 \pm 0.27$ \\
\hline Gestational age (weeks) & $30.3 \pm 2.05$ & $30.2 \pm 1.71$ \\
\hline Males (\%) & $15(75)$ & $14(70)$ \\
\hline Hospital delivery (\%) & $19(95)$ & $18(90)$ \\
\hline Cesarean section (\%) & $4(20)$ & $4(20)$ \\
\hline Birth weight < 10 ${ }^{\text {th }}$ percentile for gestational age (\%) & $2(10)$ & $2(10)$ \\
\hline Apgar score at 5 min & $7-9$ & $7-9$ \\
\hline
\end{tabular}

Table 1: Baseline characteristics of caffeine and aminophylline groups

\begin{tabular}{|c|c|c|c|c|c|}
\hline Day & $\begin{array}{c}\text { Aminophylline group } \\
(\mathrm{n}=20)(\text { Mean } \pm \text { SD) }\end{array}$ & $\begin{array}{c}\text { Caffeine group } \\
(n=20)(\text { Mean } \pm \text { SD })\end{array}$ & t-test & $P$ value & Inference \\
\hline 0 & $1.05 \pm 0.04$ & $1.09 \pm 0.10$ & 0.274 & 0.170 & Not Significant \\
\hline 1 & $0.13 \pm 0.02$ & $0.13 \pm 0.02$ & 0.468 & 0.177 & Not Significant \\
\hline 5 & $0.06 \pm 0.01$ & $0.07 \pm 0.01$ & 1.378 & 0.197 & Not Significant \\
\hline
\end{tabular}

\begin{tabular}{|c|c|c|c|c|c|c|c|}
\hline $\begin{array}{l}\text { Maturity on } \\
\text { Admission }\end{array}$ & $\begin{array}{l}\text { Drug } \\
\text { Infused } \downarrow\end{array}$ & $\begin{array}{c}\text { Not } \\
\text { Achieved }\end{array}$ & Achieved & Total & $\begin{array}{c}\text { CHI } \\
\text { Square } \\
\text { Value } \\
\left(\chi^{2}\right)\end{array}$ & P Value & Inference \\
\hline \multicolumn{8}{|l|}{ GROUP A } \\
\hline \multirow{3}{*}{$\begin{array}{l}(28-30 \\
\text { weeks) }\end{array}$} & Drug A* & $\begin{array}{c}03 \\
(42.85 \%)\end{array}$ & $\begin{array}{c}04 \\
(57.15 \%) \\
\end{array}$ & 07 & \multirow{3}{*}{0.17} & \multirow{3}{*}{0.67} & \multirow{3}{*}{ Not Significant } \\
\hline & Drug B** & $\begin{array}{c}01 \\
(16.66 \%)\end{array}$ & $\begin{array}{c}05 \\
(83.34 \%) \\
\end{array}$ & 06 & & & \\
\hline & TOTAL & $\begin{array}{c}04 \\
(30.76 \%) \\
\end{array}$ & $\begin{array}{c}09 \\
(69.24 \%) \\
\end{array}$ & 13 & & & \\
\hline \multicolumn{8}{|l|}{ GROUP B } \\
\hline \multirow{3}{*}{$\begin{array}{l}(31-33 \\
\text { weeks) }\end{array}$} & Drug A* & $\begin{array}{c}03 \\
(37.5 \%) \\
\end{array}$ & $\begin{array}{c}05 \\
(62.5 \%) \\
\end{array}$ & 08 & \multirow{3}{*}{0.26} & \multirow{3}{*}{0.60} & \multirow{3}{*}{ Not Significant } \\
\hline & Drug B ${ }^{* *}$ & $\begin{array}{c}03 \\
(37.5 \%)\end{array}$ & $\begin{array}{c}05 \\
(62.5 \%)\end{array}$ & 08 & & & \\
\hline & TOTAL & $\begin{array}{c}06 \\
(37.5 \%) \\
\end{array}$ & $\begin{array}{c}10 \\
(62.5 \%) \\
\end{array}$ & 16 & & & \\
\hline GROUP C & & & & & & & \\
\hline \multirow{3}{*}{$\begin{array}{l}\text { (34-36 } \\
\text { weeks) }\end{array}$} & $\operatorname{Drug}^{*}$ & $\begin{array}{c}02 \\
(40 \%) \\
\end{array}$ & $\begin{array}{c}03 \\
(60 \%) \\
\end{array}$ & 05 & \multirow{3}{*}{0.16} & \multirow{3}{*}{0.68} & \multirow{3}{*}{ Not Significant } \\
\hline & Drug B* & $\begin{array}{c}02 \\
(33.4 \%)\end{array}$ & $\begin{array}{c}04 \\
(66.6 \%)\end{array}$ & 06 & & & \\
\hline & TOTAL & $\begin{array}{c}04 \\
(36.36 \%)\end{array}$ & $\begin{array}{c}07 \\
(63.64 \%)\end{array}$ & 11 & & & \\
\hline
\end{tabular}

Table 3: Comparison of the efficacy of caffeine with aminophylline in the management of AOP

${ }^{*}$ Drug $\mathrm{A}=$ intravenous aminophylline

${ }^{* *}$ Drug B = intravenous caffeine 


\section{ORIGINAL ARTICLE}

\section{AUTHORS:}

1. Maulik Korvadiya

2. Rupesh Masand

3. Alok Purohit

\section{PARTICULARS OF CONTRIBUTORS:}

1. Post Graduate Resident, Department of Paediatrics, NIMS Medical College, Jaipur.

2. Associate Professor, Department of Paediatrics, NIMS Medical College, Jaipur.

3. Professor and HOD, Department of Paediatrics, NIMS Medical College, Jaipur.

\section{NAME ADDRESS EMAIL ID OF THE} CORRESPONDING AUTHOR:

Dr. Rupesh Masand,

Sector 4/467,

Malviyanagar,

Jaipur-302017,

Rajasthan.

E-mail: masand.rupesh72@gmail.com masand.rupesh@rediffmail.com

Date of Submission: 20/05/2014. Date of Peer Review: 21/05/2014. Date of Acceptance: 26/05/2014. Date of Publishing: 05/06/2014. 